\title{
MANAGEMENT OF LUNG HYDATID DISEASE: REVIEW OF 100 CASES FROM THI-QAR / IRAQ
}

\author{
Dr. Ahmed abd-alameer Daffar (M. B. CH. B., F. I. B. M. S.) \\ Thi-Qar University, College of Medicine
}

\begin{abstract}
Objective: To present the advantages of elimination of the residual cavity after lung hydatid cyst removal by capitonnage associated with closure of the bronchial openings and partial pericystectomy via thoracotomy and to compare our study made at $\mathrm{Al}$ - Hussein Teaching Hospital in Thi-Qar governorate with those done in other centers and hospitals in Iraq and outside

our country.

Patients: This is a retrospective study of 100 patients for whom thoracotomy for lung hydatid cyst(s) was carried out over a period of about three years (from 1st of January 2013 till 1st of

February 2016).

Methods: The case sheets of relevant patients for whom thoracotomy for lung hydatid cyst(s) were carried out were reviewed to collect information like patient's sex, age, nature of surgery, method of obliteration of residual cavity after removal of hydatid cyst(s), etc...

Results: All patients were admitted into AlHussein teaching hospital and thoracotomy was done for all of them regardless the age. Most of our patients suffered only from lung hydatid cyst(s) and several patients had also concomitant liver hydatid cyst(s) for which phrenotomy was

carried out at the same session of thoracotomy to deal with the liver hydatid cyst(s). This concomitant phrenotomy to deal with the liver hydatid cyst(s) made the patient in no need for another surgery (laparotomy) in the future and the number of incisions and operations. A large number of our patients had no or mild symptoms at time of examination. Higher number of patients had cough and several patients complained from hemoptysis. All patients were exposed to chest Xray, chest CT - scan and abdominal U/S before surgery. During the operation, the hydatid cyst(s) was/were removed and the evacuation technique was most commonly applied and lobectomy was very rarely carried out. After removal of hydatid cyst(s), the residual cavity was mostly obliterated (capitonnage) to prevent collection of blood, exudate and possibly pus inside residual cavity and to seal the bronchial fistulae completely and ensure rapid expansion of lung.

Conclusions: Pulmonary hydatid disease is endemic in Iraq and is diagnosed by imaging investigations and can be treated with minimal morbidity and mortality by lung preserving surgery. Elimination of the residual cavity after hydatid cyst removal by capitonnage was most commonly carried out. Hydatid disease affects children and young aged people and the
\end{abstract}


Thi-Qar Medical Journal (TQMJ): Vol.(11), No.(1), 2016

\section{utjmed@utq.edu.iq}

management is always by surgery and there is no way for conservative treatment except for dead and calcified hydatid cysts.

Investigations

\section{Radiographic imaging}

\section{A- Chest X ray}

A well defined circular or ovoid shaped opacity of homogenous density is diagnostic of a simple intact hydatid cyst. A pathognomonic radiographic finding is a "perivesicular pneumocyst". This appears as a slender crescent "signet ring" in cases of adventitial rupture. The "double arc sign" The "water-lily" A large daughter cyst with a partially or completely drained pericyst produces the "rising sun" sign.Air fluid level (lung abscess)Often, an empty cavity with remnants of collapsed membranes are seen.Rarely, all the membranes are coughed up and an "empty pulmonary cavity" surrounded by a thin margin is seen.In rare instances, the adventitia may calcify, and this gives the appearance on X-ray of a thin shell of an egg.Hydropneumothorax may be seen, and this indicates rupture into the pleural cavity.Bilatral multiple cysts is a common radiographic finding.B- CT scan of chest \& abdomen ( liver )These procedures are of great value in demonstrating the exact site, size and number of cysts.CImmunological tests,D-Blood test,E-osinophilia is a common finding,F-Parasitological testsThese are based on the finding of scolices, brood capsules and daughter cysts in the sputum or pleural aspirate.

Treatment

Surgical treatment

\section{Removal of the cyst}

The principles of removal of a hydatid cyst are evacuation of the contents of the cyst, avoidance of spillage during the procedure, closure of the bronchial fistulae, and prompt reexpansion of the lung.

\section{- Aspiration/evacuation technique}

The most appropriate method.

\section{- Enucleation}

Its disadvantage is possibility of rupture \& contamination.

\section{- Excision}

It leads to persistent air leakage + bleeding. It's not recommended nowadays.

After removal of the cyst by whatever method, the bronchial openings (fistulae) should be sutured individually. The residual sac is either left open or obliterated.

\section{Resection}

There are certain indications for this procedure \& include the following options: -

- Segmentectomy

- Lobectomy

- Pneumonectomy

This is rarely needed.

-When the disease is bilateral, the side with a large simple cyst or with a complicated cyst is operated on first.

-In patients with lung and liver involvement, the priority is for lung.

-Rupture into the pleural cavity with hydropneumothorax or pyopneumothorax mandates possibly decortication.

\section{Medical treatment}

Mebendazole is prescribed in high dosage, $50 \mathrm{mg}$ per kg per day in divided doses for three months for high risk patients. Alternatives include albendazole in a dose of $(10-15) \mathrm{mg} / \mathrm{kg} / \mathrm{day}$ in divided doses. 
Thi-Qar Medical Journal (TQMJ): Vol.(11), No.(1), 2016

utjmed@utq.edu.iq

To present the advantages of elimination

\section{Aim of study}

of the residual cavity after lung hydatid cyst removal by capitonnage associated with closure of the bronchial openings and partial pericystectomy via thoracotomy and to compare our study made at Al - Hussein Teaching Hospital in Thi-Qar governorate with those done in other centers and hospitals inside and outside our country.

\section{Patients and Methods}

This is a retrospective study of 100 patients for whom thoracotomy (mainly posterolateral thoracotomy) for lung hydatid cyst(s) was carried out over a period of about three years (from 1st of January 2013 till 1st of February 2016) in Al - Hussein Teaching Hospital in Thi - Qar governorate in Iraq.

On admission, an informative history was taken from every patient including age, sex, onset \& nature of clinical features related to the lung hydatid cyst(s). Baseline data included patient demographics, presence of comorbid diseases like hypertension, D. M. and other possible chronic diseases, presence of previous surgical operation and history of drug allergy, etc....

Every patient was exposed for clinical examination especially auscultation of the chest. The investigations which were needed before surgery included imaging studies of chest and abdomen (chest $X$-ray and chest CT-scan and abdominal $U / S$ ), virology screening for hepatitis $B$, hepatitis $C$ and HIV and other routine investigations including PCV, random blood sugar, base line renal ahmed-abdalameer@utq.edu.iq

and liver function tests and ECG. Bronchoscopy was not necessary for the patient.

Thoracotomy alone was done for patients with lung hydatid cyst(s) with no associated liver hydatid cyst(s) while patients with concomitant liver hydatid cyst(s) needed in addition a phrenotomy for dealing with the liver hydatid cyst(s). Surgery was done under general anaesthesia in left or right decubitus position and rarely in supine position. Thoracotomy is a supermajor operation and carries significant risk for the patient during and after surgery and a written consent was routinely taken from patient and his family before the surgical procedure in Al - Hussein Teaching Hospital. An apical and basal chest drain was inserted routinely at the end of operation for drainage of blood, exudate and air from the pleural space.

The patient was put routinely on injectable antibiotics postoperatively and rarely on anticoagulant for high risk patients to prevent thrombosis of deep veins of the lower limbs and possibly other thrombo-embolic phenomenon. In addition, analgesia and anti-stress ulcer medications were given routinely after surgery. Physiotherapy is important after surgery to enhance rapid inflation of the involved lung and obliterate any residual space in the thoracic cavity. Management of the patient continues on an in-patient basis for an average of 7 days but there are several patients who needed admission for longer duration in the hospital after carrying out the surgical procedure because of prolonged air leakage, delayed expansion of the involved lung and / or wound infection.

The chest drains are extracted usually inside the hospital and there is usually an interval of several days between removal of one chest drain and the other one. Then follow up continues on outpatient basis from few weeks to several months to detect \& treat complications as early as possible. After carrying 
out the surgical operation, the patient is put on albendazole tablet in a dose of $10 \mathrm{mg}$ per Kg per day in divided doses for 12 weeks to prevent recurrence of the hydatid cyst(s).

\section{Results}

Figure.1 (Sex of patiemts) the number of females (52 patients) was slightly higher than males (48 patients).

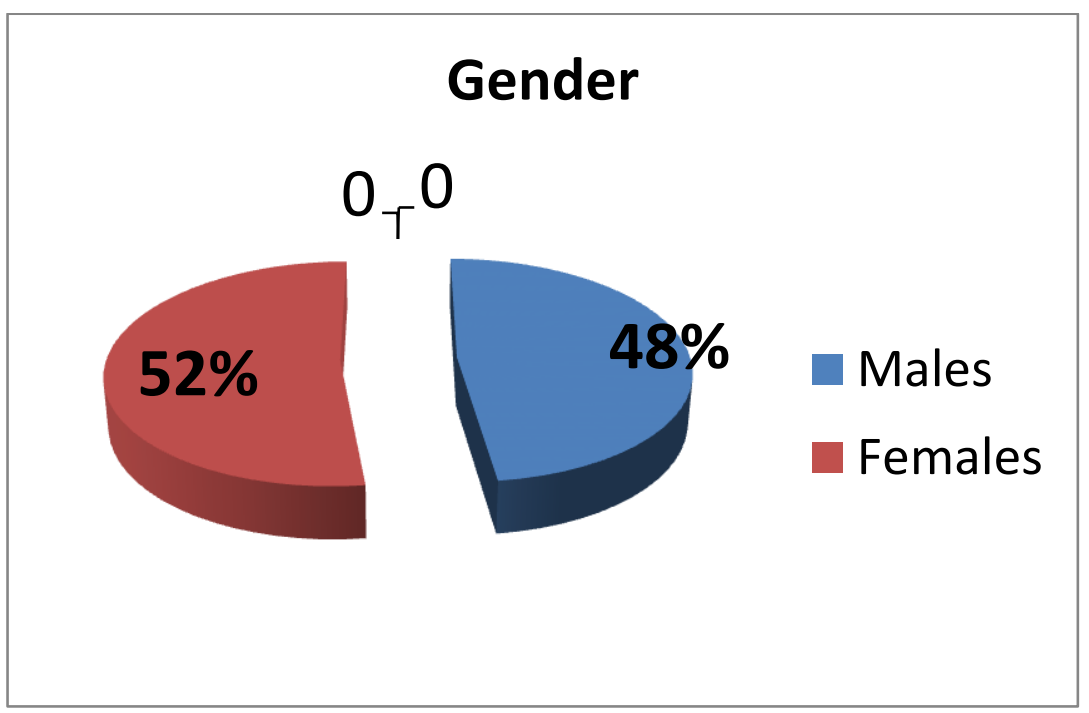

\section{Table.1 (Age distribution)}

The youngest patient was 4 years old and the oldest one was 64 years old. The highest incidence was among those below 30 years (79\%) and decreased after the age of 30 years and was uncommon after the age of 40 years. The mean age was 20.35 years.

\begin{tabular}{|c|c|c|}
\hline Age of patients & No. of patients & Percentage \\
\hline Less than 10 years & 25 & $25 \%$ \\
\hline $\mathbf{1 0 - 1 9}$ & 35 & $35 \%$ \\
\hline $\mathbf{2 0 - 2 9}$ & 19 & $19 \%$ \\
\hline $\mathbf{3 0 - 3 9}$ & 11 & $11 \%$ \\
\hline $\mathbf{4 0 - 4 9}$ & 6 & $6 \%$ \\
\hline $\mathbf{5 0 - 5 9}$ & 3 & $3 \%$ \\
\hline $\mathbf{6 0 - 6 9}$ & 1 & $1 \%$ \\
\hline Total & 100 & $100 \%$ \\
\hline
\end{tabular}


Table.2 (Site of involvement)

Thoracotomy was done for removal of lung hydatid

cyst(s). Phrenotomy was done to deal with was no significant difference between incidences of right and left sided pulmonary hydatid cysts. concomitant accessible liver hydatid cyst(s). There

\begin{tabular}{|c|c|c|}
\hline Site of involvement & No. of patients & Percentage \\
\hline Left lung ( intrapulmonary ) & 48 & $48 \%$ \\
\hline Right lung ( intrapulmonary) & 42 & $42 \%$ \\
\hline $\begin{array}{c}\text { Right lung and concomitant liver } \\
\text { involvement }\end{array}$ & 6 & $6 \%$ \\
\hline $\begin{array}{c}\text { Right intrapleural ruptured hydatid } \\
\text { cyst }\end{array}$ & 2 & $1 \%$ \\
\hline $\begin{array}{c}\text { Left lung and concomitant liver } \\
\text { involvement }\end{array}$ & 1 & $1 \%$ \\
\hline $\begin{array}{c}\text { Left intrapleural ruptured hydatid } \\
\text { cyst }\end{array}$ & 1 & $100 \%$ \\
\hline Total & 100 & $2 \%$ \\
\hline
\end{tabular}

\section{Table.3 (Presentation)}

The most common presentation of a patient with lung hydatid cyst(s) was cough and some of them presented with hemoptysis. A large number of patients were with no symptoms and had been detected accidentally.

\begin{tabular}{|c|c|c|}
\hline Presentation & No. of patients & Percentage \\
\hline Cough & 60 & $60 \%$ \\
\hline Asymptomatic & 30 & $30 \%$ \\
\hline Dyspnea & 30 & $30 \%$ \\
\hline Signs \& symptoms of lung abscess & 20 & $20 \%$ \\
\hline Hemoptysis & 15 & $15 \%$ \\
\hline Chest pain & 10 & $10 \%$ \\
\hline Annorexia \& weight loss & 10 & $10 \%$ \\
\hline Expectoration of hydatid cyst fluid & 6 & $6 \%$ \\
\hline $\begin{array}{c}\text { Expectoration of grape like } \\
\text { material }\end{array}$ & 2 & $2 \%$ \\
\hline
\end{tabular}


Thi-Qar Medical Journal (TQMJ): Vol.(11), No.(1), 2016

utjmed@utq.edu.iq

ahmed-abdalameer@utq.edu.iq

All cases had been exposed to chest CXR, chest CT-scan, abdominal U/S and routine blood investigations.

\begin{tabular}{|c|c|c|}
\hline Investigations & No. of patients & Percentage \\
\hline Chest X - Ray & 100 & $100 \%$ \\
\hline Chest CT - scan & 100 & $100 \%$ \\
\hline Abdominal CT - scan & 20 & $20 \%$ \\
\hline Abdominal U / S & 100 & $100 \%$ \\
\hline Routine blood investigations & 100 & $100 \%$ \\
\hline
\end{tabular}

Table.5 (Radioogical appearance) the most common radiological finding was water - lily sign (40\%) and least common hydro - pneumothorax (3\%)

\begin{tabular}{|c|c|c|}
\hline Radiological appearance & No. of patients & Percentage \\
\hline Water - lily sign & 40 & $40 \%$ \\
\hline $\begin{array}{c}\text { Homogenous well defined } \\
\text { opacity }\end{array}$ & 30 & $30 \%$ \\
\hline Lung abscess & 20 & $20 \%$ \\
\hline Perivesicular pneumocyst & 7 & $7 \%$ \\
\hline Hydro - pneumothorax & 3 & $3 \%$ \\
\hline Total & 100 & $100 \%$ \\
\hline
\end{tabular}

Table.6 (Method of removal of hydatid cyst)

The most common method to remove the lung hydatid cyst was by the evacuation technique and rarely by lobectomy.

\begin{tabular}{|c|c|c|}
\hline Method of hydatid cyst removal & No. of patients & Percentage \\
\hline Evacuation of ruptured cysts & 63 & $63 \%$ \\
\hline $\begin{array}{c}\text { Aspiration / evacuation } \\
\text { technique }\end{array}$ & 20 & $20 \%$ \\
\hline Enucleation & 8 & $8 \%$ \\
\hline $\begin{array}{c}\text { Evacuation of ruptured cysts } \\
\text { decortication }\end{array}$ & 3 & $3 \%$ \\
\hline Segmentectomy & 3 & $3 \%$ \\
\hline Excision & 2 & $2 \%$ \\
\hline Lobectomy & 1 & $1 \%$ \\
\hline Total & 100 & $100 \%$ \\
\hline
\end{tabular}


Thi-Qar Medical Journal (TQMJ): Vol.(11), No.(1), 2016

utjmed@utq.edu.iq

ahmed-abdalameer@utq.edu.iq

Table.7 (Dealing with residual cavity after removal of lung hydatid cyst)

The most successful method to deal with the residual cavity after removal of hydatid cyst(s) was by capitonnage associated with closure of the bronchial openings and partial pericystectomy.

\begin{tabular}{|c|c|c|}
\hline $\begin{array}{c}\text { Method of dealing with residual } \\
\text { cavity }\end{array}$ & No. of patients & Percentage \\
\hline Capitonnage & 90 & $90 \%$ \\
\hline Suturing of lung tissue & 5 & $5 \%$ \\
\hline Marsupialization & 4 & $4 \%$ \\
\hline No action & 1 & $1 \%$ \\
\hline Total & 100 & $100 \%$ \\
\hline
\end{tabular}

Table.8 (Postoperative complications)

the most common complication after surgery for lung hydatid cyst(s) was wound infection. All complications were treated conservatively with no need for invasive surgery.

\begin{tabular}{|c|c|c|}
\hline Conplications & No. of patients & Percentage \\
\hline Wound infection & 5 & $5 \%$ \\
\hline Atelectasis & 4 & $4 \%$ \\
\hline Prolonged air leakage & 1 & $1 \%$ \\
\hline Bleeding & 1 & $1 \%$ \\
\hline Empyema & 1 & $1 \%$ \\
\hline Mortality & 1 & $1 \%$ \\
\hline
\end{tabular}

\section{Discussion}

There was no great sex difference in our thesis and females (52\%) were affected only slightly more than males (48\%) and this disagrees a little bit from the thesis made by Nazar B. Elhassani and Abdulsalam Y. Taha ${ }^{(4)}$ in which $(57 \%)$ of the patients were women. This could be due to the fact that women in rural areas are closely associated with domestic and farm duties, such as milking animals and cultivating crops while most men are military or government personnel. In contrast, some authors reported slightly higher prevalence among males ${ }^{[5][6]}$.

Patients become infected with E. granulosus and the cyst grows very slowly, so symptoms may not appear and the disease may not be diagnosed until many years later. 
Thi-Qar Medical Journal (TQMJ): Vol.(11), No.(1), 2016

\section{utimed@utq.edu.iq}

Hydatid disease is seen in subjects of any age

and sex, but affects mainly children and young aged people unlike hypertension, diabetes mellitus and ischemic heart disease which affect middle aged and old aged people.

The youngest patient in our thesis was 4 years old and the oldest one was 64 years old. The highest incidence was among those below 30 years (79\%) and decreased after the age of 30 years and was uncommon after the age of 40 years. The mean age was 20.35 years. This agrees with the study made by Nazar B. Elhassani and Abdulsalam Y. Taha ${ }^{(4)}$ in which about sixty percent of the patients were in the second and third decades of life and the youngest patient was two and a half years old.

The right lung was affected similarly to the left lung in our thesis and most of the lung hydatid cysts were intrapumonary and rarely ruptured to the pleural space. This disagrees with the study made by Nazar B. Elhassani and Abdulsalam Y. Taha ${ }^{(4)}$ in which the right lung was affected by about $65 \%$ of the cases while the left lung was affected by $35 \%$ of

patients.

The clinicl features of hydatid disease depend on size and site of the lesion. Slowly growing echinococcal cysts generally remain with no symptoms until their expanding size and their space occupying effect in the lung elicits symptoms. Therefore, doctors working in endemic countries or treating patients from endemic areas should be aware of hydatid disease. It is important to remember that HC may have very unusual presentations.
Haemoptysis may be found in cases with both simple and complicated cysts (infected and/or ruptured), although it is more common in the latter. High fever characterizes the onset of infection or rupture of a cyst. Signs and symptoms of sepsis are common in suppurative cysts with fetid contents.

The most common presentation of patients in our study with lung hydatid cyst(s) was cough (60\%). A significant number of patients were dyspnic (30\%). Other patients were asymptomatic (30\%) and diagnosed accidentally. Some of our patients presented with hemoptysis $(15 \%)$ or chest pain $(10 \%)$.

This is similar to the study made by Nazar B.

Elhassani and Abdulsalam Y. Taha ${ }^{(4)}$ in which the most common presentation was also cough while other presentations were less common.

All patients (100\%) in our study were exposed to chest X-ray, chest CT-scan and abdominal U/S while abdominal CT -scan was carried out only for those (20\%) with positive findings by abdominal U/S. Bronchoscopy was not needed for evaluation of the patients with lung hydatid cyst(s) except for one patient in which there was a suspicion of presence of malignancy.

Bronchoscopy is unnecessary in cases of ruptured PHC with a pathognomonic clinical picture, radiologic picture or both. However, it is indispensable when there is suspicion of tumor or when the radiologic picture is atypical. This agrees with the the study made by Nazar B. Elhassani and Abdulsalam Y. Taha ${ }^{(4)}$. in which bronchoscopy was part of the diagnostic work-up of 4 patients suffering 
Thi-Qar Medical Journal (TQMJ): Vol.(11), No.(1), 2016

utjmed@utq.edu.iq

from haemoptysis with suspicion of tumour. In the study made by Nazar B. Elhassani and Abdulsalam Y. Taha ${ }^{(4)}$, bronchoscopy was diagnostic in a case of middle lobe $\mathrm{HC}$ by seeing a laminated membrane protruding through the offended bronchus.

The most common radiological finding was

water - lily sign (40\%) and less commonly homogenous well defined opacity (30\%) \& lung abscess (20\%) and rarely hydro - pneumothorax (3\%). This differs from the thesis made by Nazar B. Elhassani and Abdulsalam Y. Taha ${ }^{(4)}$ in which a homogenous rounded-oval opacity could be identified in about $60 \%$ of the patients and water-lily sign was seen less commonly in about (20\%) while lung abscess was seen in about (10\%) of their cases and hydropneumothorax in only about (3\%) of the patients. More signs and symptoms are seen in patients with lung hydatid cysts after they become complicated because of either rupture or infection or both while uncomplicated hydatid cysts are characterized by being asymptomatic until reaching a significant size.

The aim of surgery in pulmonary hydatid cyst

is to remove the cyst completely while preserving the lung tissue as much as possible. Lung resection is performed only if there is an irreversible and disseminated pulmonary destruction. Lung preserving surgery was done in more than $90 \%$ of patients while lobectomy was necessary only very rarely. The most common method to remove the lung hydatid cyst was by the evacuation technique $(63 \%)$ while aspiration / evacuation technique could be achieved in $(20 \%)$ of cases and enucleation in $(8 \%)$ of the patients.
Lobectomy was carried out very rarely (1\%). This is due to the fact that hydatid cysts are usually complicated rather than being intact. This disagrees slightly with the thesis made by Nazar B. Elhassani and Abdulsalam Y. Taha ${ }^{(4)}$ in which the most common methods of removal of hydatid cyst(s) were the aspiration / evacuation technique and for a similar number of patients the the evacuation technique and less commonly the enucleation technique and least commonly excision and resection techniques.

There are two methods for management of the residual cyst cavity: capitonnage which means closure of the residual cavity after removing its contents with serial purse string sutures starting from the bottom outwards and marsupialization which includes closure of bronchial orifices leaving the cavity open associated with partial pericystectomy and eversion of the edges of residual cavity. Which option is better? This is a very controversial issue. There are several studies which either encourages capitonnage or discourages marsupialization and vice versa. We share many authors their opinion that capitonnage is the best way to deal with the residual cavity after removal of hydatid cyst. This is due to the fact that obliteration of the space occupied previously by the hydatid cyst prevents infection (empyema \& lung abscess), controls air leakage and minimizes the possibility of broncho-pleural fistula formation, prevents collection of blood, exudates and other types of fluids in residual cavity after removal of hydatid cyst. This will enhance lung expansion and decreases the postoperative stay inside the hospital. On the other hand, marsupialization is characterized by higher rate of infection, air 
Thi-Qar Medical Journal (TQMJ): Vol.(11), No.(1), 2016

\section{utimed@utq.edu.iq}

leakage, collections and prolonged postoperative stay inside the hospital.

Al-Ali and Baram claimed that low complication rate was achieved following capitonnage in 72 cases of PHC ${ }^{[7]}$. On the other hand, several studies including that made by Nazar B. Elhassani and Abdulsalam Y. Taha (4) see that capitonnage is unnecessary [7] [8] [9] and recommend leaving the residual sac open to obliterate spontaneously after closure of bronchial fistulae and emphasize that no attempt should be made to suture it. Moreover, Sarsam ${ }^{[8]}$ believe that obliteration of the cavities of multiple cysts, particularly when large, may convert the remaining lung tissue into a collapsed and distorted mass, prone to infection and other complications. Our study encourages capitonnage of residual cavity after removal of hydatid cyst and this technique was applied on $90 \%$ of our patients and this differs completely from the study made by Nazar B. who see that .Elhassani and Abdulsalam Y. Taha (4) capitonnage is unnecessary and they prefer to leave the residual cavity open ( marsupialization ) and this technique was applied on most of their patients.

Not infrequently, thoracic surgeons are asked

for the management of hydatid cysts located at the upper part (subdiaphragmatic location) of the liver. A thoracotomy provides better exploration and access to the cyst located in this area when compared to laparotomy. Seven patients were managed by this approach in our study. This fact agrees with the thesis made by Nazar B. Elhassani and Abdulsalam Y. Taha (4). Percutaneous aspiration has not been accepted or reported as a therapeutic option for pulmonary ahmed-abdalameer@utq.edu.iq

hydatidosis in Iraq, however, thoracoscopic removal of few PHCs has been reported once ${ }^{(\mathbf{1 0})}$.

In this study, we observed that complications

such as wound infection, atelectasis, prolonged air leak, bleeding and empyema seemed to be higher following surgery for ruptured than intact cysts. All complications could be treated by conservative measures with no need for doing open surgery again. The aforementioned complications increased the morbidity of the patients and increased the inhospital stay after surgery. The number of patients affected by these complications and their nature is acceptable. One of our patients who were 55 years old died after two hours from surgery and the cause of death was ischemic heart disease (myocardial infarction). The postoperative complications in our study and their management agree with those seen in the study made by Nazar B. Elhassani and Abdulsalam Y. Taha ${ }^{(4)}$.

\section{Conclusions}

1-Pulmonary hydatid disease is endemic in Iraq and is diagnosed by imaging investigations (X-ray, CT-scan) and concomitant liver hydatid cyst(s) are detected by abdominal U/S and CT-scan.

2-Pulmonary hydatid disease is treated with minimal morbidity and mortality by lung preserving surgery.

3-Elimination of the residual cavity after hydatid cyst removal by capitonnage associated with closure of the bronchial openings and partial pericystectomy via thoracotomy was most commonly carried out. 
Thi-Qar Medical Journal (TQMJ): Vol.(11), No.(1), 2016

\section{utjmed@utq.edu.iq}

4-Trans-diaphragmatic removal of liver hydatid cyst(s) was done for those with concomitant liver hydatid cyst(s) at the same session of thoracotomy.

5-Hydatid disease affects children and young aged people unlike hypertension, diabetes mellitus and ischemic heart disease which affect middle aged and old aged people.

6-Hydatid disease in any part of body needs always surgical treatment and there is no way for conservative treatment except for dead and calcified hydatid cysts. ahmed-abdalameer@utq.edu.iq

\section{Recommendations}

1-Capitonnage associated with closure of the bronchial openings and partial pericystectomy is the best way to deal with the residual cavity after removal of pulmonary hydatid cyst(s).

2-Sanitation is the best way to control infectious diseases including hydatid disease.

3-Vegetables should be cleaned well before eating.

4- Clean water supply is mandatory to prevent transmission of different diseases including hydatid disease. 
Thi-Qar Medical Journal (TQMJ): Vol.(11), No.(1), 2016

utjmed@utq.edu.iq ahmed-abdalameer@utq.edu.iq

\section{References}

1-"Echinococcosis Fact sheet N ${ }^{\circ} 377 "$. World Health Organization. March 2014. Retrieved 19 March 2014.

2-Tappe D, Stich A, Frosch M (February 2008). "Emergence of polycystic neotropical echinococcosis". Emerging Infect. Dis. 14 (2): 292-7. doi:10.3201/eid1402.070742. $\underline{\text { PMC }} \underline{2600197 .}$ PMID 18258123.

3-Canda MS, Canda T, Astarcioglu H, Güray M (2003). "The Pathology of Echinococcosis and the Current Echinococcosis Problem in Western Turkey" (PDF). Turk J Med Sci 33: 369-374.

4-Nazar B. Elhassani1, Abdulsalam Y. Taha2\#, Management of Pulmonary Hydatid Disease: Review of 66 Cases from Iraq, Iraqi Board of Medical Specializations and Scientific Council of Thoracic and Cardiovascular Surgery, Baghdad, Iraq, published 10 March 2015.

5- Kavukcu, S., Kilic, D., Tokat, A.O., Kutlay, H., Cangir, A.K., Enon, S., et al. (2006) Parenchyma-Preserving Surgery in the Management of Pulmonary Hydatid Cysts. Journal of Investigative Surgery, 19, 61-68. http://dx.doi.org/10.1080/08941930500444586

6-Bagheri, R., Haghi, S.Z., Amini, M., Fattahi, A.S. and Noorshafiee, S. (2011) Pulmonary Hydatid Cyst: Analysis of 1024 Cases. Journal of Thoracic and Cardiovascular Surgery, 59, 105-109.

7-Taha, A.Y. (2013) To Close or Not to Close: An Enduring Controversy. A Letter to Editor. Archive of International Surgery, 3, 254-255. http://dx.doi.org/10.4103/22789596.129582

8-Sarsam, A. (1971) Surgery of Pulmonary Hydatid Cysts: Review of 155 Cases. The Journal of Thoracic and Cardiovascular Surgery, 62, 465-469.

9-Shehatha, J., Alizzi, A., Alward, M. and Konstantinov, I. (2008) Thoracic Hydatid Disease: A Review of 763 Cases. Heart, Lung and Circulation, 17, 502-504. http://dx.doi.org/10.1016/i.hlc.2008.04.001

10- Almajed, S. (2012) Video-Assisted Thoracoscopic Removal of Pulmonary Hydatid Cyst: Initial Experience in Nassyria. Thi-Qar Medical Journal, 6, 171-172.

الخلاصة

الهيف: تقديم مزايا القضاء على التجويف المتبقي بعد إز الة الاكياس المائية بطريقة (كابيتوناجي) المرتبطة بإغلاق فتحات

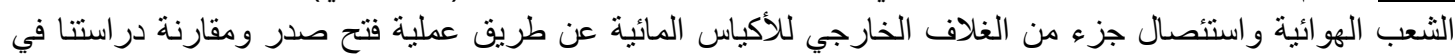


Thi-Qar Medical Journal (TQMJ): Vol.(11), No.(1), 2016

\section{utjmed@utq.edu.iq}

ahmed-abdalameer@utq.edu.iq

مستشفى الحسين التعليمي في محافظة ذي قار مع تلك التي نم انجاز ها في سائر المر اكز والمستشفيات في العر اق وخارج بلدنا.

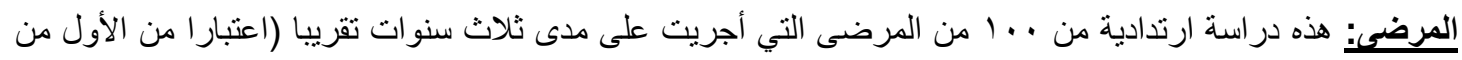

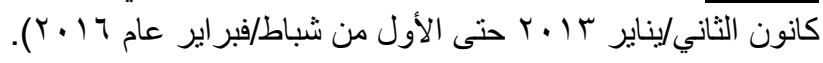

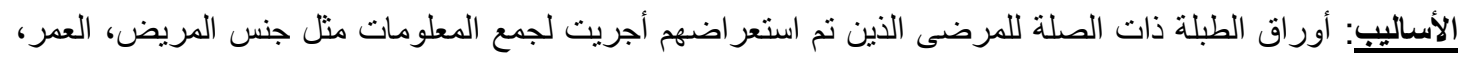

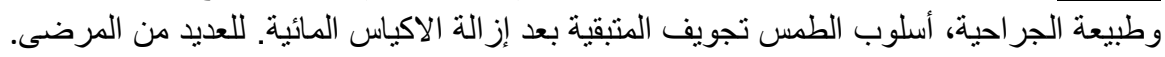

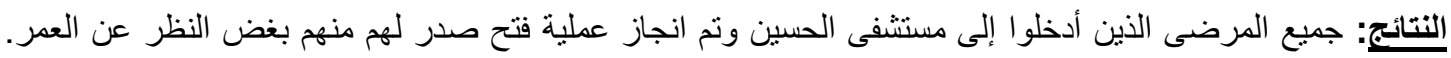

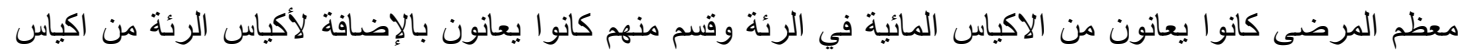

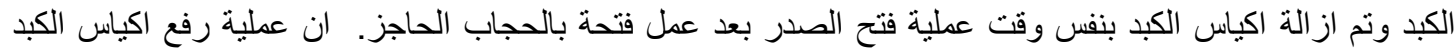

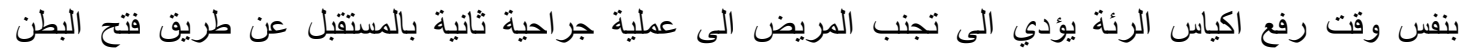

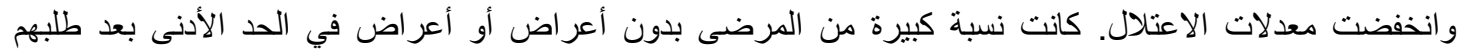

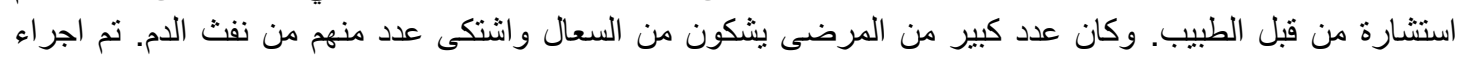

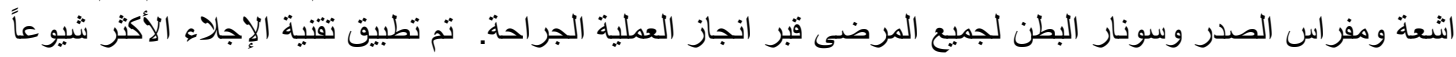

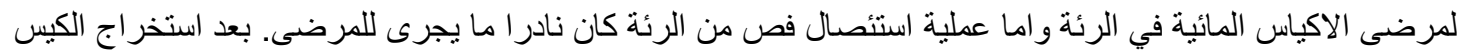

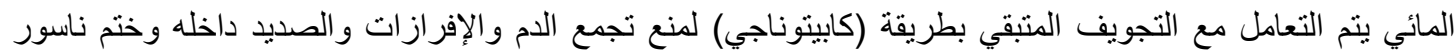
الثعب الهو ائية تماما وضمان التوسع السريع في الرئة.

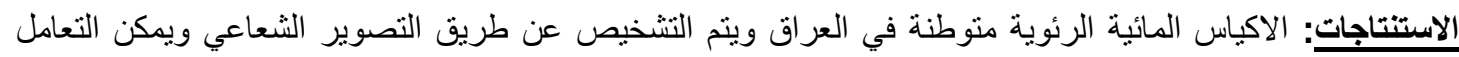

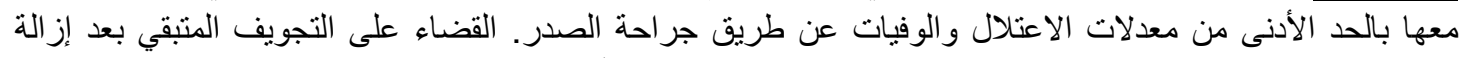

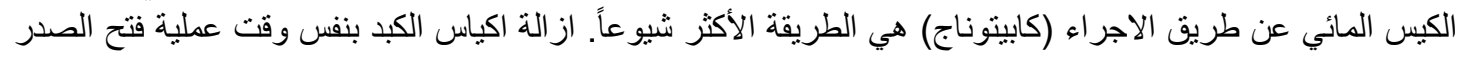

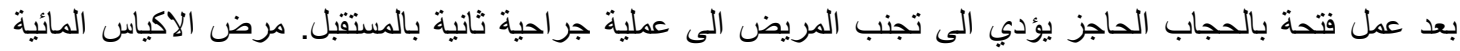

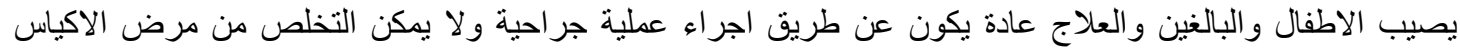
المائية بالطرق التحفظية عدا الاكياس المائية الميتة و المتكلسة. 